\title{
Sistem Informasi Pencatatan Arus Kas (SIPAS) Pada PKBM Negari 23 Kebon Melati Jakarta Menggunakan Model Waterfall
}

\author{
Ibnu Rusdi' ${ }^{1}$, Fitri Andriani ${ }^{2}$ \\ email: ibnu.ibr@nusamandiri.ac.id, andrianif969@gmail.com \\ Sekolah Tinggi Manajemen Informatika dan Komputer Nusa Mandiri \\ Universitas Bina Sarana Informatika
}

\begin{abstract}
Abstrak
Pusat Kegiatan Belajar Masyarakat (PKBM) Negeri 23 Kebon Melati Jakarta Pada saat ini sistem pengolahan kas masih dengan pencatatan manual, mulai dari pencatatan penerimaan dan pengeluaran kas, proses penyimpanan data-data yang berhubungan dengan transaksi kas, sampai dengan pembuatan laporan. sehingga memungkinkan pada saat proses berlangsung akan terjadi kesalahan dalam pencatatan, kurang akuratnya laporan yang dibuat, dan keterlambatan dalam pencarian data-data yang diperlukan. Sistem komputerisasi dibutuhkan untuk menghasilkan pencatatan transaksi aru kas menjadi lebih baik pada PKBM Negeri 23 Kebon Melati Jakarta menjadi serta lebih efektif dan efisien. Dalam pengembangan sistem komputerisasi penerapan metode System Life Development System (SDLC) menggunakan Waterfall dengan tahapan yang terdapat dalam metode tersebut dapat dihasilkan sistem informasi pencatatan arus kas dengan memanfaatkan teknologi yang digunakan dan dapat dioperasikan secara optimal agar menghasilkan laporan arus penerimaan serta pengeluaran yang dihasilkan dari pengolahan data dapat dipergunakan sebagai mestinya.
\end{abstract}

Kata kunci : Sistem Informasi, Pencatatan Arus Kas, Model Waterfall

\section{Pendahuluan}

PKBM Negeri merupakan satuan pelaksana Dinas Pendidikan dalam penyelenggaraan Pendidikan Nonformal bagi masyarakat. Pusat Kegiatan Belajar Masyarakat (PKBM) Negeri 23 Kebon Melati Jakarta menyelenggarakan pendidikan kesetaraan paket A, paket B, dan paket C. Dalam pengelolaan keuangan PKBM Negeri 23 Kebon Melati masih menggunakan sistem yang belum terkomputerisasi, yang mana melakukan kegiatan penerimaan siswa, kegiatan disekolah serta pencatatan dan penyimpanan data penerimaan maupun pengeluaran kas masih dengan buku jurnal. Menurut (Kabuhung, 2013) kas berperan sebagai media pertukaran yang terlibat langsung maupun tidak langsung pada sebagian besar transaksi.

Kegiatan penerimaan dan pengeluaran kas merupakan hal yang sangat penting sehingga dibutuhkan sistem informasi arus kas yang dapat meningkatkan kecepatan dan ketepatan dalam pengolahan data-data penerimaan dan pengeluaran kas. Dengan menggunakan teknologi komputer sebagai alat pencatatan dan penyimpanan data-data penerimaan dan pengeluaran kas, maka sistem informasi akuntansi arus transaksi kas pada PKBM Negeri 23 Kebon Melati Jakarta diharapkan dapat menjadi lebih efektif dan efisien.

Teknologi komputerisasi merupakan salah satu cara atau alat yang dapat membantu penyelesaian pekerjaan pada era yang semakin canggih seperti saat ini. Setiap perusahaan atau instansi baik dalam sekala kecil maupun besar dapat dipastikan membutuhkan teknologi canggih seperti komputer baik yang digunakan secara manual maupun dengan menggunakan data elektronik. Menerapkan Metode System LifeCycle Development (SDLC) dengan model Waterfall pengembangan sistem informasi pencatatan arus kas pada PKBM Negeri 23 Kebon Melati Jakarta mengikuti setiap tahap dan dengan dukungan data yang diperoleh dari bagian tata usaha dalam hal ini yang mengelola penerimaan dan pengeluaran kas, penulis mendapatkan gambaran 
mengenai proses bisnis sampai dengan implementasi aplikasi sistem yang diterapkan tentunya membutuhkan pelatihan dalam masa transisi penerapan sistem informasi pencatatan arus kas (SIPAS). Kendala-kendala selama proses implementasi akan menjadi masukan bagi penulis sehingga dapat dilakukan penyesuaian dan pengguna mudah dalam menggunakannya.

\section{Metode Penelitian}

Menurut (Hutahaean, 2014) "Sistem informasi adalah suatu system didalam suatu organisasi yang mempertemukan kebutuhan pengelolaan transaksi harian, mendukung operasi, bersifat manajerial, dan kegiatan strategi dari suatu organisasi dan menyediakan pihak luar tertentu dengan laporan-laporan yang dibutuhkan".

Menurut (Kabuhung, 2013) Kas adalah salah satu unsur aktiva yang paling penting karena merupakan alat pertukaran atau pembayaran yang siap dan bebas digunakan untuk membiayai kegiatan operasional perusahaan. Menurut (Maknunah, 2015) Penerimaan kas adalah perolehan harta dalam bentuk kas yang diterima oleh perusahaan dari customer ketika membeli barang. Menurut (Maknunah, 2015) mengemukakan bahwa "Sistem akuntansi pengeluaran kas terdapat sistem akuntansi pokok yang bisa digunakan dalam sistem akuntansi pengeluaran kas yaitu sistem akuntansi pengeluaran kas dengan cek dan sistem akuntansi pengeluaran kas dengan uang tunai melalui dana kas kecil".

Menurut (Sukamto \& Salahudin, 2018) "Entity Relationship Diagram (ERD) merupakan bentuk paling awal dalam melakukan perancangan basis data relasional".

Menurut (Kuryanti, 2016) dalam Tabrani "Logical Record Structure (LRS) dibentuk dengan nomor dari tipe record".

Menurut (Cahyaningtyas \& Iriyani, 2015) mengemukakan bahwa "visual basic merupakan sebuah bahasa pemrograman yang menawarkan Intergrated Development Environment
(IDE) visual untuk membuat program perangkat lunak berbasis operasi Microsoft Windows menggunakan model pemrograman(COM)".

Menurut (Kusrini \& Koniyo, 2007) "Crystal report merupakan program yang dapat digunakan untuk membuat, menganalisis dan menterjemahkan informasi yang terkandung dalam database atau program ke dalam berbagai jenis laporan yang sangat flexibel".

Menurut (Lutfiana, 2015) mengemukakan bahwa: "crystal report merupakan program khusus untuk membuat laporan yang terpisah dari program Microsoft Visual Basic 6.0, tetapi keduanya dapat dihubungkan (linkage)".

\section{Hasil dan Pembahasan}

A. Prosedur Sistem Berjalan

Berikut adalah prosedur sistem berjalan sistem penerimaan dan pengeluaran kas anatara lain:

1. Prosedur Penerimaan kas

a) Penyaluran dana BOS adalah untuk penyediaan pendanaan biaya non- personalia, adapun untuk investasi dan personil hanya pada golongan tertentu, dan untuk tambahan kas sekolah kepada bendahara untuk keperluan perlengkapan sekolah yang telah ditetapkan pemerintah. Pengambilan dana BOS dilakukan oleh bendahara dengan membawa surat rekomendasi, memeriksa rekening bank lalu mencairkan dana bos dan mencatat dana masuk kedalam jurnal.

b) Setiap awal bulan siswa/i juga melakukan pembayaran uang iuran SPP dengan proses yaitu siswa membawa kartu iuran SPP ke bagian tata usaha lalu bagian tata usaha mencatat transaksi pada kartu iuran kemudian dibubuhi stampel sekolah lalu dicatat pada buku jurnal.

c) Siswa juga melakukan pembayaran uang daftar ulang 
setiap awal semester baru, yaitu bagian tata usaha langsung mencatat kedalam jurnal dan meberikan bukti kwitansi pembayaran daftar ulang dengan ditanda tangani dan juga stempel.

2. Prosedur Pengeluaran Kas

a) Guru/karyawan mengajukan untuk pembelian perlengkapan seperti ATK, alat-alat kebersihan, biaya perawatan peralatan sekolah dan lain-lain, kemudian bendahara mengkonfirmasi ke kepala sekolah, ketika kepala sekolah menyetujui pengajuan maka langsung memberikan dana tersebut kepada guru/karyawan yang bersangkutan. Kemudian guru/karyawan yang mengajukan dana memberikan kwitansi bukti belanja kepada bendahra dan dicatat kedalam jurnal, disimpan kedalam arsip bukti kas keluar.

b) Bendahara juga mengeluarkan dana untuk tagihan listrik bulanan prosesnya dilakukan oleh bendahara sendiri dengan melakukan pembayaran, kemudian menerima bukti transaksi biaya tagihan listrik dan mencatat bukti tersebut kedalam buku jurnal, dan bukti tansaski diarsipkan.

c) Bendahara juga melakukan pembayaran gaji guru/karyawan setiap bulan dengan mencetak daftar nama-nama guru/karyawan beserta honor yang didapatkan berdasarkan rekapitulasi absensi kehadiran guru/karyawan. Yang bersangkutan menandatangani dan bendahara membubuhkan stempel pada kwitansi lalu menyerahkan uang gaji beserta kwitansi tanda terima gaji. Dokumen yang ditandatangani diduplikat untuk diarsipkan sebagai bukti kas keluar.

3. Prosedur Pembuatan Laporan

Bendahara membuat laporan penerimaan dan laporan pengeluaran kas tiap bulan ke kepala sekolah. Dengan dibuat dua rangkap pada masing-masing laporan ketika kepala sekolah sudah menyetujui laporan, laporan tersebut dibuat dua rangkap, laporan pada lembar pertama di setujui kepala sekolah dan laporan kedua disimpan untuk di arsipkan.

B. Perancangan Sistem Informasi

1. Kebutuhan Pengguna

Program sistem penerimaan dan pengeluaran kas pada PMKB Negeri 23 Kebon Melati belum terkomputerisasi, agar lebih efisien maka dibuatlah program dengan menggunakan beberapa user. Berikut ini analisa kebutuhan (analyst requirement) dari program sistem tersebut sebagai berikut:

a. Sekenario akses Bendahara

1) Bendahara dapat melakukan login

2) Bendahara dapat memproses penerimaan kas

3) Bendahara dapat memproses pengeluaran kas

4) Bendahara dapat memproses jurnal umum

5) Bendahara dapat melihat dan mencetak laporan : akun, penerimaan kas, pengeluaran kas dan jurnal umum

6) Bendahara dapat melakukan ubah password

7) Bendahara dapat melakukan exit

b. Sekenario akses Kepala Sekolah

1) Kepala Sekolah dapat melakukan login 
2) Kepala Sekolah dapat mengolah data akun

3) Kepala Sekolah dapat mengolah data user

4) Kepala Sekolah dapat mengolah data Saldo Awal

5) Kepala Sekolah dapat melakukan ubah password

6) Kepala Sekolah dapat melakukan exit

2. Kebutuhan Sistem

a. Pengguna melakukan login sesuai dengan hak akses masing-masing user dengan memasukan user id dan password pada aplikasi SIPAS.

b. Sistem informasi akan logout otomatis saat pengguna tidak ada aktivitas selama beberapa menit dan pengguna diingatkan untuk melakukan hal yang sama jika ingin menutup aplikasi.

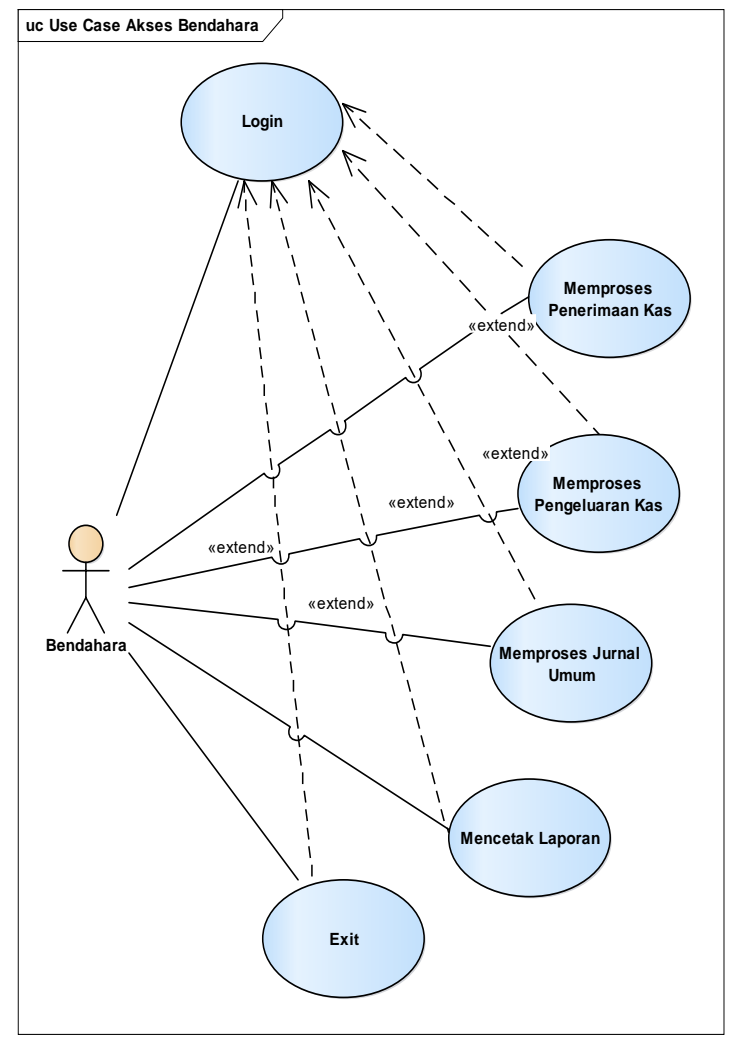

Gambar 1. Diagram Use Case SIPAS dengan actor Bendahara

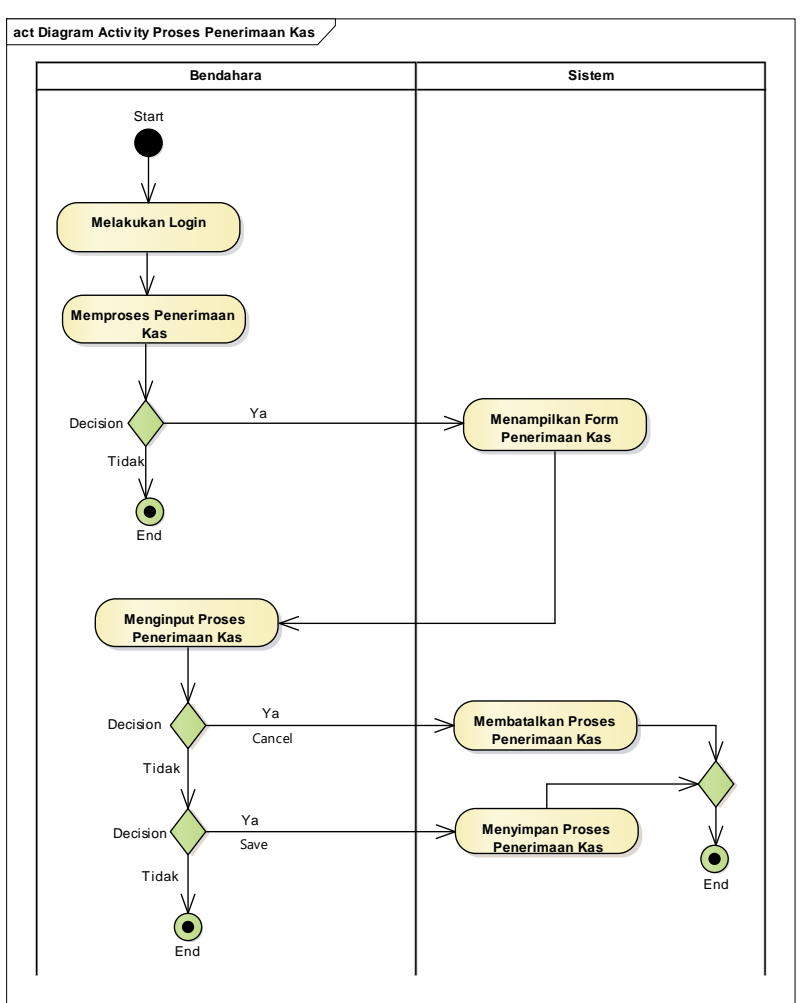

Gambar 2. Activity Diagram Prosedur Penerimaan Kas

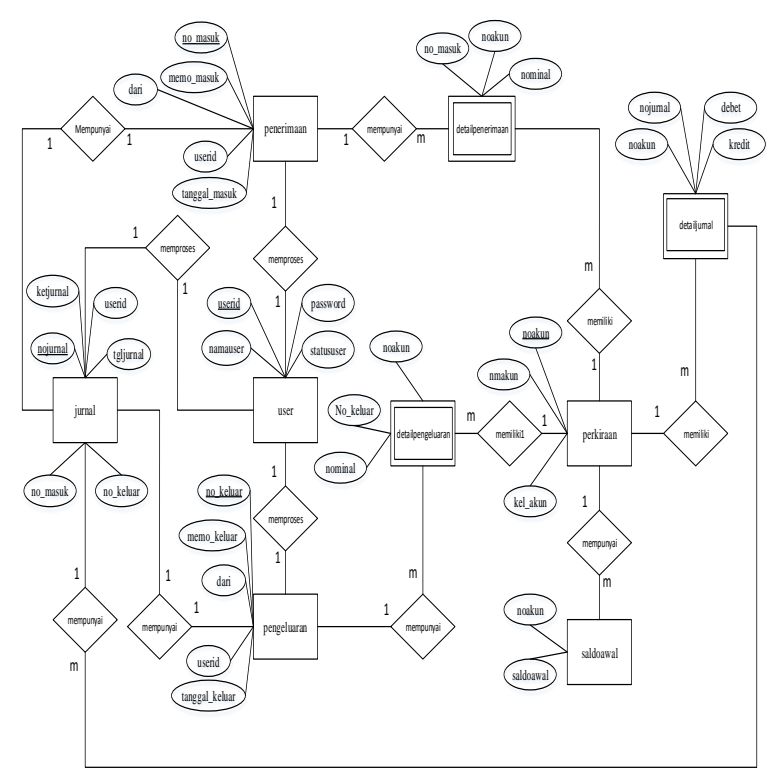

Gambar 3. ER-D Sistem Informasi Pencatatan Arus Kas 


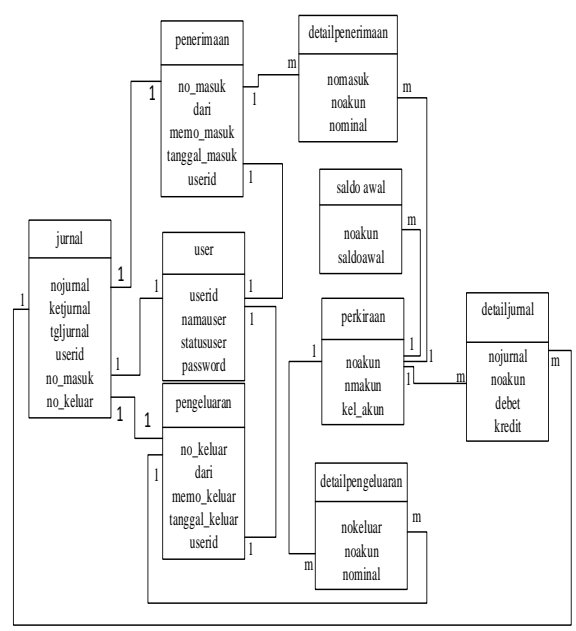

Gambar 4. LRS Sistem Informasi Pencatatan Arus Kas

C. Implementasi

1. Tampilan Form Login

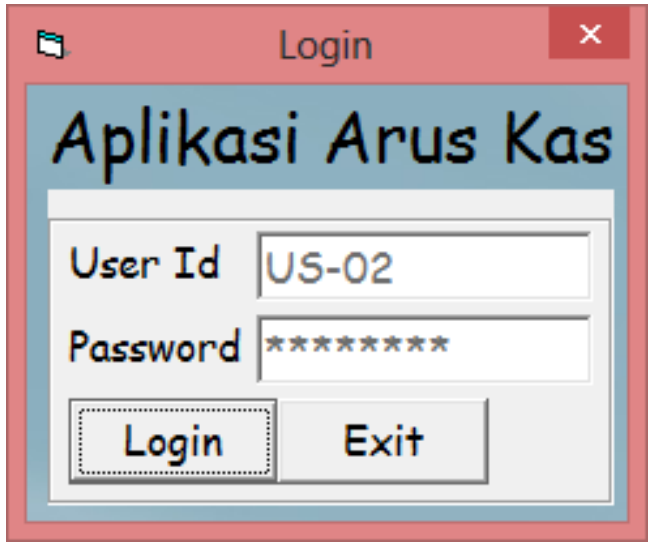

Gambar 5. Tampilan Form Login

2. Tampilan Menu Utama

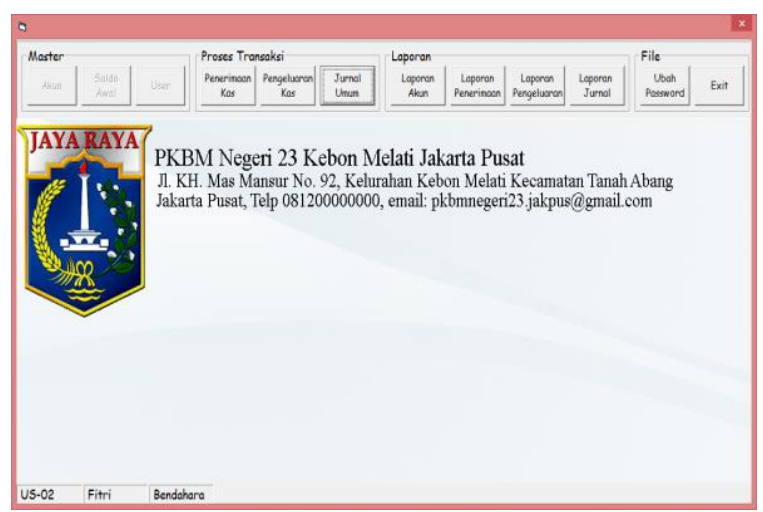

Gambar 6. Menu Utama Sistem
3. Tampilan Form Data Akun

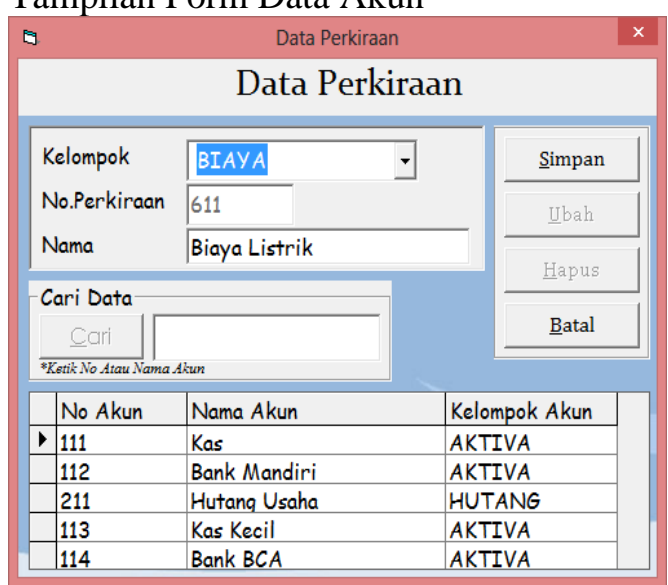

Gambar 7. Form Data Akun Perkiraan

4. Tampilan Form Saldo Awal

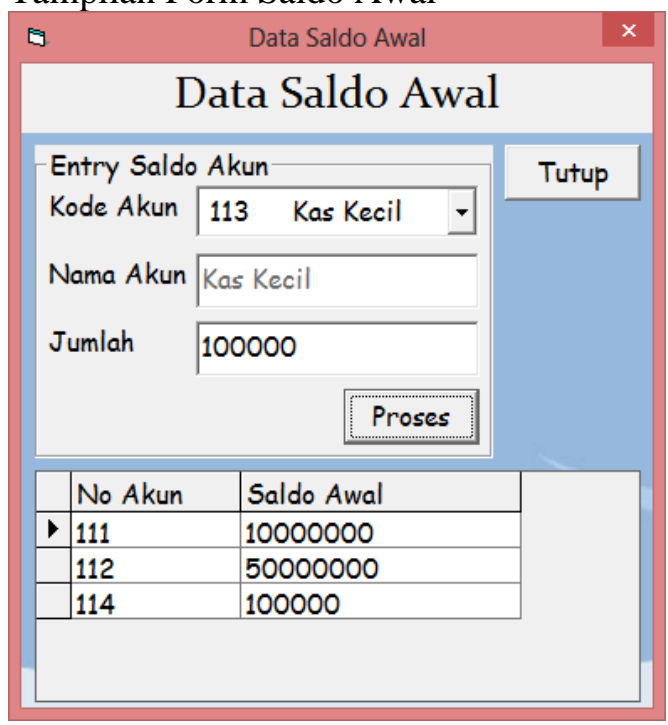

Gambar 8. Form Saldo Awal Sistem

5. Tampilan Form Penerimaan Kas

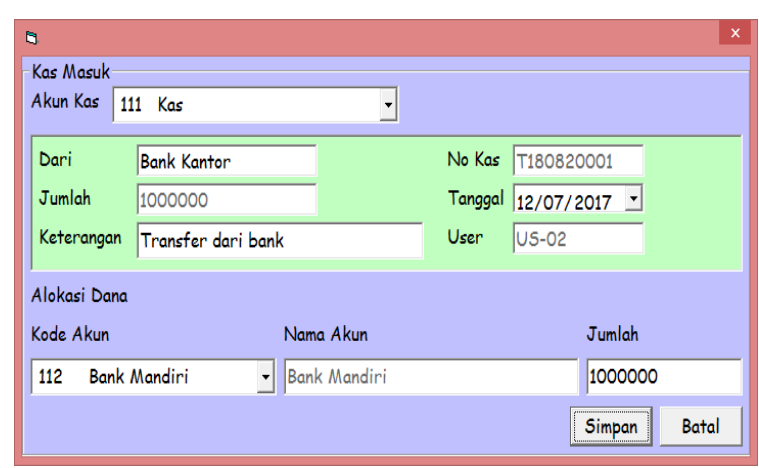

Gambar 9. Form Penerimaan Kas 


\section{Tampilan Form Pengeluaran Kas}

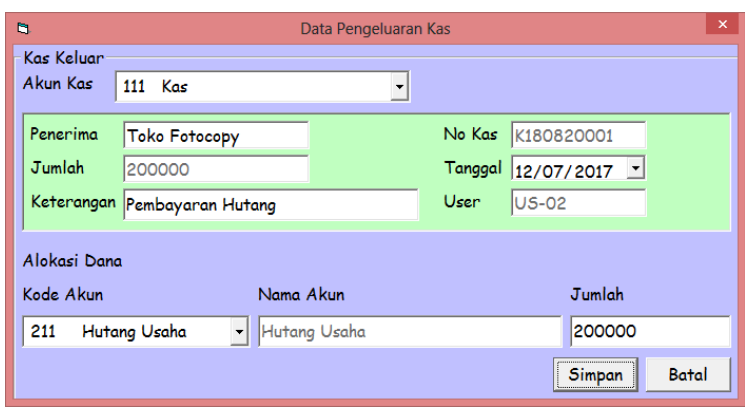

Gambar 10. Form Pengeluaran Kas

7. Tampilan Form Laporan Arus Kas

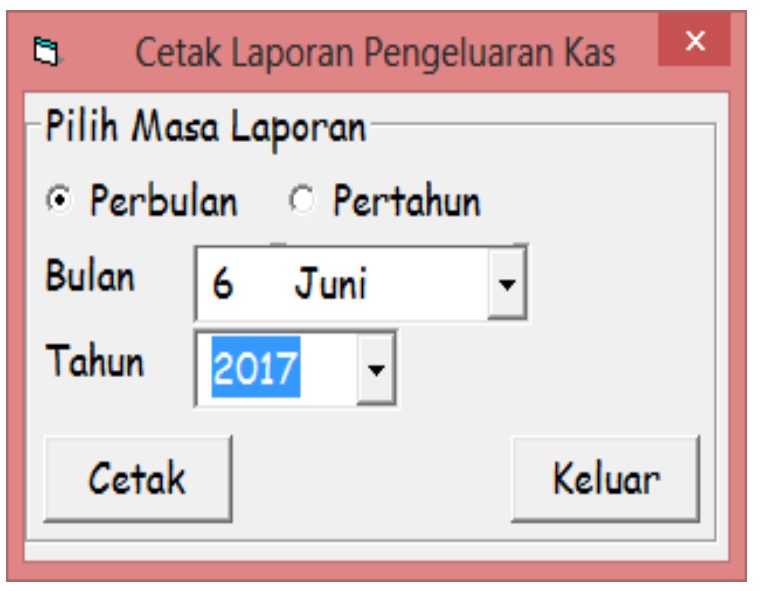

Gambar 11. Form Cetak Laporan Penegluaran Kas

D. Testing (Blackbox Testing)

Tabel 1.

Hasil Pengujian Form Kas Masuk

\begin{tabular}{lllll}
\hline No & $\begin{array}{l}\text { Skenario } \\
\text { Pengujian }\end{array}$ & $\begin{array}{l}\text { Test } \\
\text { Case }\end{array}$ & $\begin{array}{l}\text { Hasil yang } \\
\text { diharapkan }\end{array}$ & $\begin{array}{l}\text { Hasil } \\
\text { Pengujian }\end{array}$ \\
\hline 1 & Data & Data & Sistem akan & Sesuai \\
& diinput & dinnput & menyimpan & Harapan \\
& lengkap, & lengkap & data ke & \\
& lalu klik & & tabel & \\
& Simpan & & &
\end{tabular}

\section{Kesimpulan}

Kesimpulan yang dapat diambil setelah menguraikan system penerimaan dan pengeluaran kas pada PKBM Negeri 23 Kebon Melati Jakarta adalah :
1. Data-data pada proses penerimaan dan pengeluaran kas masih berupa arsip dalam bentuk kertas, hal ini sangat rentan hilang, terselip atau sobek, sehingga menyulitkan saat proses pembuatan laporan atau apabila data dibutuhkan untuk keperluan lain yang sifatnya segera.

2. Permasalahan yang juga timbul bila menggunakan sistem manual ini adalah efektifitas pelayanan pada proses kegiatan sekolah, bila suatu waktu sedang banyak kegiatan maka proses penerimaan dan pengeluaran kas akan memakan waktu dan mempengaruhi kelancaran kegiatan di PKBM Negeri 23 Kebon Melati Jakarta.

3. Dengan adanya masalah pada sistem berjalan pada penerimaan dan pengeluaran kas pada PKBM Negeri 23 Kebon Melati Jakarta, Penulis terdorong untuk mengusulkan sistem yang terkomputerisasi pada sistem penerimaan dan pengeluaran kas tersebut.

4. Dengan menggunakan sistem terkomputerisasi, penggunaan arsip dalam bentuk kertas dapat dikuranggi karena semua data-data sudah tersimpan dalam bentuk file-file yang cukup disimpan pada hard disk.

5. Selain dari itu, dengan sistem Kesimputäkomputerisasi pembuatan laporan atau pencarian data lainnya menjadi lebih mudah karena hanya mengambil data dari beberapa file menggunakan kunci utama.

\section{Daftar Pustaka}

[1] Cahyaningtyas, R., \& Iriyani, S. (2015). Perancangan Sistem Informasi Perpustakaan Pada Smp Negeri 3 Tulakan, Kecamatan Tulakan Kabupatean Pacitan. Indonesian Journal on Networking and Security, $4(2), \quad 15-20 . \quad$ Retrieved from https://ijns.org/journal/index.php/ijns/ar 
ticle/view/1308

[2] Hutahaean, J. (2014). Konsep Sistem Informasi. Yogyakarta: Deepublish. Retrieved from https://books.google.co.id/books?hl=en $\& \mathrm{l}=\& \mathrm{id}=08 \mathrm{LjCAAAQBAJ} \& \mathrm{oi}=\mathrm{fnd} \& \mathrm{p}$ $\mathrm{g}=\mathrm{PR} 7 \& \mathrm{dq}=\mathrm{konsep}+$ sistem+informasi+ jeperson+hutahaean+pdf\&ots=tr7yjLSaH\&sig=czY2IIz54vMNUJvrSppbWBhHYw\&redir_esc $=\mathrm{y} \# \mathrm{v}=\mathrm{o}$ nepage $\& q \& f=$ false

[3] Kabuhung, M. (2013). Sistem Informasi Akuntansi Penerimaan Dan Pengeluaran Kas Untuk Perencanaan Dan Pengendalian Keuangan Pada Organisasi Nirlaba Keagamaan. Jurnal Ekonomi Dan Bisnis, 1(3), 339-348. https://doi.org/10.1017/CBO978110741 5324.004

[4] Kuryanti, S. J. (2016). Rancang Bangun Sistem E-Learning sebagai Sarana Pemberlajaran Sandra. Jurnal Khatulistiwa Informatika, 4(1), 84-92. https://doi.org/10.1089/pho.2010.2784

[5] Kusrini, K., \& Koniyo, A. (2007). Tuntunan Praktis Membangun Sistem Informasi Akuntansi dengan Visual Basin dan Microsoft SQL Server. Yogyakarta: Andi Offset. Retrieved from

https://books.google.co.id/books?id=Na KZX-

XsJdEC\&pg=PA264\&dq=Crystal+repo $\mathrm{rt}+$ merupakan+program+yang+dapat+di gunakan+untuk+membuat,+menganalis is+dan+menterjemahkan+informasi+ya ng+terkandung+dalam+database+atau+ program+ke+dalam+berbagai+jenis+lap oran+yang+sangat+flexibel\&hl=en\&sa $=$ X\&ved $=2$ ahUKEwj0pbD7vbvuAhVi6 3MBHTGEAkEQ6AEwAHoECAUQA $\mathrm{g} \# \mathrm{v}=$ onepage $\& \mathrm{q}=$ Crystal report merupakan program yang dapat digunakan untuk membuat $\% 2 \mathrm{C}$ menganalisis dan menterjemahkan informasi yang terkandung dalam database atau program ke dalam berbagai jenis laporan yang sangat flexibel $\& \mathrm{f}=$ false

[6] Lutfiana, L. (2015). Aplikasi Microsoft Visual Basic 6 . 0 Sistem Persediaan Pada Toko Cat Utama Putra Semarang, 23(1), 77-96.
[7] Maknunah, J. (2015). Temu Kembali Informasi Big Data Menggunakan Kmeans Clustering Pengembangan Sistem Login Hotspot dengan Perantara Sosial Media Strategi Pemasaran Menggunakan Metode Kombinasi SWOT Dan AHP (Studi Kasus: STMIK Pradnya Paramita) Analisis Sistem Informasi Ak. Jurnal Informatika STIKI, 05(ISSN 20870256), 27-29.

[7] Sukamto, R. A., \& Salahudin, M. (2018). Rekayasa Perangkat Lunak Terstruktur Dan Berorientasi Objek (Edisi Revisi). Bandung: Informatika. Retrieved from https://scholar.google.co.id/scholar?hl=i d\&as_sdt $=0,5 \&$ cluster $=4129280622857$ 038994 